Research Article

\title{
Decisions on Dual-Channel Supply Chains under Market Fluctuations and Dual-Risk Aversion
}

\author{
Guangdong Liu $\mathbb{D},{ }^{1,2,3}$ Tianjian Yang, ${ }^{2}$ Yao Wei, ${ }^{1,3}$ and Xuemei Zhang $\mathbb{D}^{1,3}$ \\ ${ }^{1}$ School of Business, Fuyang Normal University, Fuyang, China \\ ${ }^{2}$ School of Economics and Management, Beijing University of Posts and Telecommunications, Beijing, China \\ ${ }^{3}$ Anhui Provincial Key Laboratory of Regional Logistics Planning and Modern Logistics Engineering, Fuyang, China
}

Correspondence should be addressed to Xuemei Zhang; xmz@mail.ustc.edu.cn

Received 3 December 2019; Accepted 26 December 2019; Published 29 January 2020

Academic Editor: Maria Alessandra Ragusa

Copyright (c) 2020 Guangdong Liu et al. This is an open access article distributed under the Creative Commons Attribution License, which permits unrestricted use, distribution, and reproduction in any medium, provided the original work is properly cited.

\begin{abstract}
Considering market fluctuations and risk aversion, this paper analyzes the decisions of a dual-channel supply chain consisting of one manufacturer and one retailer and compares the differences in the centralized structure, manufacturer-dominated structure, retailer-dominated structure, and Nash equilibrium structure. This paper also analyzes the impacts of market fluctuations and risk aversion on supply chain profits. The results show that the direct selling price is not influenced by market fluctuations and risk aversion under the retailer's risk aversion, and the manufacturer-dominated structure and the retail price, direct selling price, and wholesale price in other power structures are negatively correlated with market fluctuations and risk aversion, but the order quantity in the four power structures is positively correlated with market fluctuations and risk aversion, and the profits of supply chain are impacted differently by the market fluctuations and risk aversion.
\end{abstract}

\section{Introduction}

The popularity of the Internet and the enhancement of consumers' willingness to shop online have forced an increasing number of enterprises to open online markets, such as IBM, Lenovo, and Dell, and retail enterprises have also launched online competition to improve their competitiveness, such as Wal-Mart, Gome, and SUNING. The online direct marketing channel has changed the original market management mode and has rendered competition in the existing market more intense, and it has also aggravated the conflict between manufacturers and retailers. Therefore, the operation of the dual-channel supply chain has widely been concerned by scholars at home and abroad. However, the dual-channel management model weakens the limitations of the traditional market time and space, making the cognition of both sides of the transaction more superficial. At the same time, the virtual nature of the trading environment will bring electronic contracts, product quality problems, and online unfair competition, leaving the online market unstable. In addition, the intensification of market competition will bring market fluctuations and will also bring unpredictable risks to manufacturers and retailers, causing manufacturers and retailers to avoid risks and make decisions that are not conducive to the development of supply chains. Therefore, it is increasingly important to study the influence of supply chain risk aversion and market fluctuations on supply chain decision-making, especially the different risk-averse behaviors of supply chain members and the different influences of stochastic market fluctuations on supply chain decision-making against the background of dual-channel supply channels.

Currently, the research on risk aversion dual-channel supply chains is mainly based on manufacturer-led structures, involving two models of supply chains. First one is the centralized and decentralized models of traditional supply chains. Li and Zhang [1] established a risk-averse dualchannel supply chain model based on the method of absolute risk value and studied the pricing strategies of supply chains under different power structures. The influences of the 
manufacturer's risk aversion and the retailer's risk aversion on different pricing were analyzed with an example. Xu et al. [2] considered the problem of dual-channel supply chain coordination when both the manufacturer and the retailer are risk averse, using only price contracts and two-way income sharing contracts to coordinate supply chains. Zhang and Yao [3] considered the dual-channel supply chain with consumer returns. The influences of simultaneous risk aversion on supply chain decisions by manufacturers and retailers were studied by establishing centralized and decentralized game models. Zhang and Yao [4] studied the influences of consumer returns and market demand fluctuations on risk-averse dual-channel decisionmaking. $\mathrm{Xu}$ and Zhang [5] considered the coordination problem based on price discounts when both the manufacturer and the retailer avoid risk in a dual-channel supply chain with random demand. Yan et al. [6] considered the dual-channel supply chain with a manufacturer-dominated structure and risk aversion and analyzed the influence of risk aversion on supply chain decisions when market demand is disturbed. Yan et al. [7] considered a dual-channel supply chain composed of a risk-averse supplier and a risk-neutral retailer and established demand-disturbance and risk-averse supply chain models under centralized and decentralized modes, respectively. The decisions of the supply chain before and after demand fluctuation were compared.

Second is the decentralized supply chain model. Li et al. [8] considered a two-stage supply chain composed of one manufacturer and one retailer and analyzed the influence of the risk aversion of both on supply chain decision-making under competition and cooperation modes. Li et al. [9] studied the supply chain of perishable products with leading supplier and retailer's risk aversion; they compared the pricing strategies when the retailer is risk neutral, and the retailer is risk averse based on the risk value and conditional risk value and coordinated the supply chain by risk and revenue-sharing contracts. Liu et al. [10] considered the dual-channel supply chain of consumers' residual, established decentralized game models when both the manufacturer and retailer are risk averse, and compared the different decisions of supply chains under complete information and asymmetric information. Wang et al. [11] studied the influence of risk aversion of the manufacturer and the retailer at the same time on the decisions of the supply chain under the condition of asymmetric information and compared the equilibrium strategies under the situations of information symmetry and asymmetric information. Wang et al. [12] studied information sharing in the dual-channel supply chain under the retailer's risk preference and compared the decisions of the supply chain in the information sharing mode. Chen and $\mathrm{Hu}$ [13] studied the effects of risk aversion on the supply chain under the three modes of dual-channel supply chains. It was found that the risk aversions of the manufacturer and the retailer have different influences on the supply chain, and the selling price and wholesale price are the best in the dual-channel mode of horizontal concentration. Shen and Liu [14] considered the influences of risk aversion and carbon emissions efforts on the decisions of supply chains under the three scenarios of dual-channel supply chains when the manufacturer is dominant.

It can be found from the above literature that the research on dual-channel supply chains when the manufacturer is dominant has mainly involved the traditional mode in the early stage and, in recent years, research on the decentralized model has been relatively common. However, there exists literature on risk-averse dual-channel supply chains. Yan and Liu [15] studied the dual-channel supply chain under dominant and risk-averse retailers and analyzed the changes in the supply chain before and after demand disruption under the decentralized mode. Fang et al. [16] considered the dual-channel supply chain under dominant and risk-averse retailers in the condition of stochastic demand and analyzed the pricing and expected utility of the centralized and decentralized models, which were established. In the Nash equilibrium mode, Wang and Zhou [17] considered the pricing of a dual channel of single and alternative products. Li et al. [18] studied the dual-supply chain of perishable products with a risk-averse retailer and analyzed the influence of risk aversion on supply chain decisions under a Nash equilibrium game and different demand disruption scenarios. It can be seen that there has been less literature on retailer-dominant and Nash equilibrium structures.

In conclusion, the existing literature includes two cases: on the one hand, the manufacturer and the retailer are risk averse at the same time under a manufacturer-dominant structure, while the retailer is risk averse when the retailer is leading; on the other hand, the manufacturer and the retailer are risk averse at the same time, or the retailer is risk averse in a Nash equilibrium game. However, in fact, the different power structures render the different attitudes of the manufacturer and the retailer to the obvious risk: the manufacturer has more rights when the manufacturer is dominant, and the risk-averse attitude of the retailer as a follower is more obvious, in greater accord with the psychological expectations of the participants. The manufacturer shows a more obvious risk-averse attitude when the retailer is dominant. In addition, the effect of demand fluctuations on the dual-channel supply chain has not been studied under the condition of stochastic demand. Therefore, in the aforementioned literature, the risk aversion of the supply chain under a power balance was studied, and the risk aversion of the follower was analyzed when the power was not balanced, and this paper compares the decisions of the two-channel supply chain by establishing game models under the three different power structures of the centralized mode-the manufacturer-dominant mode, retailer-dominant mode, and Nash equilibrium mode-and analyzes the influences of market fluctuations on the decisions of the dual-channel supply chain to obtain different management enlightenment and to improve the research on dual-channel supply chain management. In addition, the widest impact of these market models on environmental ecosystems could be considered $[19,20]$.

The rest of this paper is organized as follows. Section 2 is the model description, which mainly explains the four types of power structures and establishes the models. Section 3 
analyzes the risk-averse supply chain in the centralized mode, the structure of a risk-averse retailer and a dominant manufacturer, the structure of a dominant retailer and a risk-averse manufacturer, and the Nash equilibrium structure of dual-risk aversion. Section 4 compares the decisionmaking under different power structures and draws different research conclusions. Section 5 is the numerical analysis to draw analytic conclusions and the potential regular pattern. Section 6 is a summary of the paper and suggestions for future research.

\section{Model Description}

This paper analyzes a dual-channel supply chain composed of a manufacturer and a retailer and studies four different power structures, namely, the centralized structure (c), manufacturer-led structure $(\mathrm{m}-\mathrm{s})$, retailer-led structure ( $\mathrm{r}$ s), and Nash equilibrium structure (n), as shown in Figure 1. The manufacturer can sell products through both the retailer and a direct channel and determine wholesale prices and direct selling prices, while the retailer can determine retail prices. To make the manufacturer profitable, there is $p_{r}>w$.

The risk value is evaluated by the mean-variance method according to the literature, such as H.-S. Lau and A. H.-L. Lau [21] and Choi et al. [22], whereby the utility function of the risk-averse supply chain is as follows:

$$
u(\pi)=E(\pi)-k \sqrt{\operatorname{var}(\pi)},
$$

where $\operatorname{var}(\pi)=E[\pi-E(\pi)]^{2}$, and it is the variance of the profit of supply chain which is studied in the paper.

In addition, under a risk-averse supply chain, the influence of the market scale on decision-making is greater than that of risk aversion and market fluctuation, that is, $a>k_{i} \sigma, i=m, r . k_{m}$ and $k_{r}$ are the risk-aversion coefficients of the manufacturer and retailer, respectively, and $\sigma$ is the fluctuation coefficient of market demand and $\sigma>0$ [4]. For comparative analysis, it is assumed that the supply chain has the same attitude toward risk aversion [23], that is, $k_{m}=k_{r}=k>0$.

The demand functions of the retail channel and the direct channel are as follows: according to Hua et al. [24] and Huang et al. [25],

$$
\begin{aligned}
D_{r} & =\varphi a_{0}-\alpha_{r} p_{r}+\beta p_{d}, \\
D_{d} & =(1-\varphi) a_{0}-\alpha_{d} p_{d}+\beta p_{r} .
\end{aligned}
$$

To simplify the operation, it is supposed that the manufacturing cost is zero $[26,27]$, from which the profit functions of the retailer and manufacturer can be obtained as follows:

$$
\begin{aligned}
\pi_{r} & =\left(p_{r}-w\right) D_{r}, \\
\pi_{m} & =p_{d} D_{d}+w D_{r},
\end{aligned}
$$

where $r$ means the retail channel, $d$ means the direct channel, $D$ is the total demand of the supply chain, $D_{r}$ is the retail channel demand, $D_{d}$ is the direction channel demand, $\pi_{r}$ is the profit of the retailer, $\pi_{m}$ is the profit of the manufacturer, $\varphi$ is the consumer preference degree of the retail channel, $\tilde{a}$ is the potential random demand of the market, $\widetilde{a}=a+\varepsilon$, and $\varepsilon \sim N\left(0, \sigma^{2}\right), \alpha_{r}$ and $\alpha_{d}$ are the self-pricing sensitivity coefficients of the retail and direct channels, respectively, and $\beta$ is the cross-pricing sensitivity coefficient. At the same time, it is assumed that the demand is more affected by the custom price than cross-pricing, that is, $\alpha_{i}>\beta, i=r, d$.

\section{Decision Analysis under the Different Power Structures}

3.1. Decisions of the Centralized Structure. In the centralized structure, the expected profit function of the supply chain is as follows:

$$
E\left(\pi_{c}\right)=p_{r} D_{r}+p_{d} D_{d},
$$

where $\pi_{c}$ is the profit of the centralized supply chain, the supply chain is risk averse, and the variance of supply chain profit is as follows:

$$
\operatorname{var}\left(\pi_{c}\right)=E\left[\pi_{c}-E\left(\pi_{c}\right)\right]^{2}=\left[\varphi p_{r}+(1-\varphi) p_{d}\right]^{2} \sigma^{2} .
$$

The utility function of the centralized supply chain is as follows:

$$
\begin{aligned}
u\left(\pi_{c}\right)= & E\left(\pi_{c}\right)-k \sqrt{\operatorname{var}\left(\pi_{c}\right)} \\
= & p_{r}\left(\varphi a-\alpha_{r} p_{r}+\beta p_{d}\right)+p_{d}\left[(1-\varphi) a-\alpha_{d} p_{d}+\beta p_{r}\right] \\
& -k \sigma\left[\varphi p_{r}+(1-\varphi) p_{d}\right] .
\end{aligned}
$$

The first-order optimal conditions of the utility function of the supply chain in relation to the retail price and the direct selling price are as follows:

$$
\begin{aligned}
& \frac{\partial u\left(\pi_{c}\right)}{\partial p_{r}}=\varphi(a-k \sigma)-2 \alpha_{r} p_{r}+2 \beta p_{d}, \\
& \frac{\partial u\left(\pi_{c}\right)}{\partial p_{d}}=(1-\varphi)(a-k \sigma)-2 \alpha_{d} p_{d}+2 \beta p_{r} .
\end{aligned}
$$

According to formulas (7) and (8), the Hessel matrix of the utility function is as follows:

$$
\left[\begin{array}{cc}
-2 \alpha_{r} & 2 \beta \\
2 \beta & -2 \alpha_{d}
\end{array}\right]=4 \alpha_{r} \alpha_{d}-4 \beta^{2}>0 .
$$

The value of the Hessel matrix is positive, so there is the optimal value of $p_{c r}$ and $p_{c d}$ in the centralized supply chain, obtained according to formulas (7) and (8):

$$
\begin{aligned}
& p_{c r}=\frac{(a-k \sigma)\left[\varphi \alpha_{d}+(1-\varphi) \beta\right]}{2\left(\alpha_{r} \alpha_{d}-\beta^{2}\right)}, \\
& p_{c d}=\frac{(a-k \sigma)\left[\varphi \beta+(1-\varphi) \alpha_{r}\right]}{2\left(\alpha_{r} \alpha_{d}-\beta^{2}\right)} .
\end{aligned}
$$

According to formulas (10) and (11), the quantity of market demand is obtained as follows:

$$
Q_{c}=E(D)=\frac{a+k \sigma}{2} .
$$




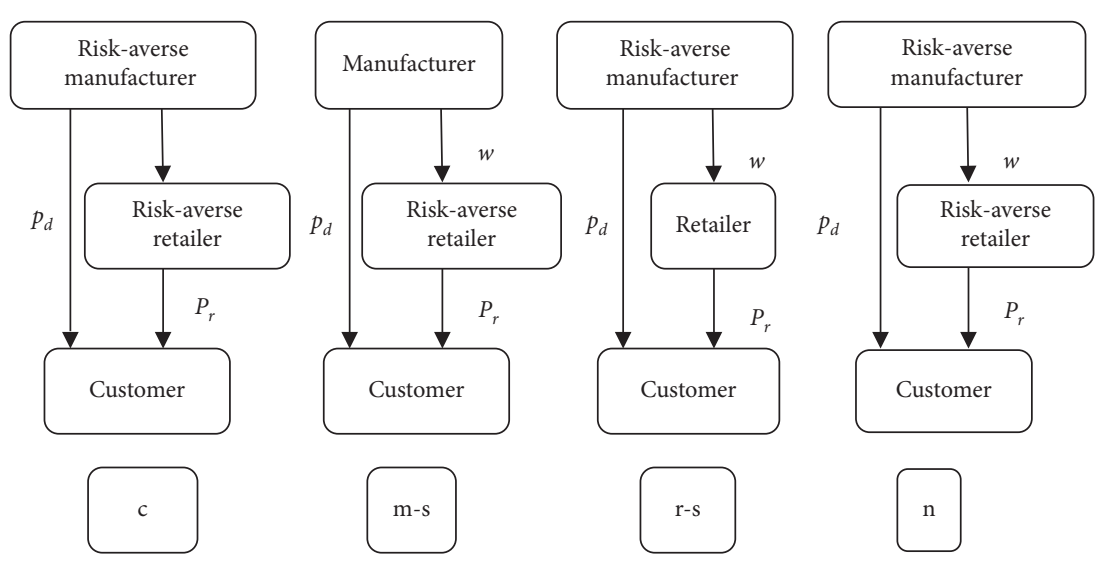

FIgURE 1: The structures of the dual-channel supply chain.

Proposition 1. In the centralized supply chain, the coefficient of risk preference and market demand fluctuation are negatively correlated with retail price and direct selling price and positively correlated with order quantity.

Proof. The first-order derivatives of $k$ and $\sigma$ are obtained according to formulas (10) and (11).

$$
\begin{aligned}
& \frac{\partial p_{c r}}{\partial k}=-\frac{\sigma\left[\varphi \alpha_{d}+(1-\varphi) \beta\right]}{2\left(\alpha_{r} \alpha_{d}-\beta^{2}\right)}<0, \\
& \frac{\partial p_{c r}}{\partial \sigma}=-\frac{k\left[\varphi \alpha_{d}+(1-\varphi) \beta\right]}{2\left(\alpha_{r} \alpha_{d}-\beta^{2}\right)}<0, \\
& \frac{\partial p_{c d}}{\partial k}=-\frac{\left[\varphi \beta+(1-\varphi) \alpha_{r}\right]}{2\left(\alpha_{r} \alpha_{d}-\beta^{2}\right)}<0, \\
& \frac{\partial p_{c d}}{\partial \sigma}=-\frac{k\left[\varphi \beta+(1-\varphi) \alpha_{r}\right]}{2\left(\alpha_{r} \alpha_{d}-\beta^{2}\right)}<0 .
\end{aligned}
$$

The first-order derivatives of $\sigma$ and $k$ are obtained according to formula (12):

$$
\begin{aligned}
& \frac{\partial Q_{c}}{\partial k}=\frac{\sigma}{2}, \\
& \frac{\partial Q_{c}}{\partial \sigma}=\frac{k}{2} .
\end{aligned}
$$

It can be known from the model description that $\sigma$ is the fluctuation coefficient of market demand and $\sigma>0$ and $k$ is the degree of risk aversion and $k>0$, so it can be obtained that $\left(\partial Q_{c} / \partial k\right)=(\sigma / 2)>0$ and $\left(\partial Q_{c} / \partial \sigma\right)=(k / 2)>0$.

Thus, Proposition 1 is tenable.

As seen from Proposition 1, the retail price and the direct selling price decrease with the increases in risk aversion and market fluctuation, but the order quantity is increased with the increases in risk preference and market fluctuation, showing that the greater that the risk is and the greater that the market fluctuation is, the lower that the retail price and direct selling price are. Therefore, the goal of stabilizing the market share can be achieved by reducing the retail price and the direct selling price, as well as increasing the order quantity; at the same time, the risk caused by risk aversion and market fluctuations can be reduced.

3.2. Models under the Risk-Averse Retailer and Dominant Manufacturer. The variance is obtained by the expected profit function as follows:

$$
\operatorname{var}\left(\pi_{r}\right)=E\left[\pi_{r}-E\left(\pi_{r}\right)\right]^{2}=\left[\sigma \varphi\left(p_{r}-w\right)\right]^{2} .
$$

The utility function of the retailer is as follows:

$$
\begin{aligned}
u\left(\pi_{r}\right) & =E\left(\pi_{r}\right)-k \sqrt{\operatorname{var}\left(\pi_{r}\right)} \\
& =\left(p_{r}-w\right)\left(\varphi a-\varphi k \sigma-\alpha_{r} p_{r}+\beta p_{d}\right) .
\end{aligned}
$$

The first-order derivative of the retailer is obtained by the utility function:

$$
\frac{\partial u\left(\pi_{r}\right)}{\partial p_{r}}=\varphi a-\varphi k \sigma-2 \alpha_{r} p_{r}+\beta p_{d}+\alpha_{r} w .
$$

Therefore, the optimal price of the retail is calculated when the manufacturer is dominant:

$$
p_{r}=\frac{\varphi a-\varphi k \sigma+\beta p_{d}+\alpha_{r} w}{2 \alpha_{r}}
$$

The expected profit function of the manufacturer is as follows according to formula (18).

$$
\begin{aligned}
E\left(\pi_{m}\right)= & \frac{w}{2}\left(\varphi a+\varphi k \sigma+\beta p_{d}-\alpha_{r} w\right)+p_{d}[(1-\varphi) a \\
& \left.-\alpha_{d} p_{d}+\frac{\beta}{2 \alpha_{r}}\left(\varphi a-\varphi k \sigma+\beta p_{d}+\alpha_{r} w\right)\right] .
\end{aligned}
$$

Therefore, the optimal conditions of the wholesale price and the direct price can be obtained:

$$
\begin{aligned}
& \frac{\partial E\left(\pi_{m}\right)}{\partial w}=-\alpha_{r} w+\beta p_{d}+\frac{1}{2}(a+k \sigma) \\
& \frac{\partial E\left(\pi_{m}\right)}{\partial p_{d}}=\beta w+2\left(\frac{\beta^{2}}{2 \alpha_{r}}-\alpha_{d}\right) p_{d}+(1-\varphi) a+\frac{\varphi \beta}{2 \alpha_{r}}(a-k \sigma) .
\end{aligned}
$$

The Hessel matrix is as follows: 


$$
\left[\begin{array}{cc}
-\alpha_{r} & \beta \\
\beta & \frac{\beta^{2}}{\alpha_{r}}-2 \alpha_{d}
\end{array}\right]=2\left(\alpha_{r} \alpha_{d}-\beta^{2}\right)>0,
$$

where $-\alpha_{r}<0$ and $2\left(\alpha_{r} \alpha_{d}-\beta^{2}\right)>0$, and the Hessel matrix is definitely positive, so there is the optimal wholesale price and direct price. Combining formulas (20) and (21), the optimal direct price $p_{m d}$, the optimal wholesale price $w_{m}$, and the optimal retail price $p_{m r}$ and the optimal order quantity $Q_{m}$ can be obtained when the manufacturer is dominant as follows:

$$
\begin{aligned}
& p_{m d}=\frac{\left[\varphi \beta+(1-\varphi) \alpha_{r}\right] a}{2\left(\alpha_{r} \alpha_{d}-\beta^{2}\right)}, \\
& w_{m}=\frac{\left[\varphi \alpha_{d}+(1-\varphi) \beta\right] a}{2\left(\alpha_{r} \alpha_{d}-\beta^{2}\right)}+\frac{\varphi k \sigma}{2 \alpha_{r}}, \\
& p_{m r}=\frac{\left[\varphi\left(\beta^{2}+\alpha_{r} \alpha_{d}\right)+2(1-\varphi) \beta \alpha_{r}\right] a}{4 \alpha_{r}\left(\alpha_{r} \alpha_{d}-\beta^{2}\right)}+\frac{\varphi(2 a-k \sigma)}{4 \alpha_{r}}, \\
& Q_{m}=E(D)=\frac{a}{2}-\frac{\varphi\left(\alpha_{r}-\beta\right)(a-k \sigma)}{4 \alpha_{r}} .
\end{aligned}
$$

Proposition 2. When the manufacturer is dominant, and the retailer is risk averse, the direct selling price is not affected by risk aversion and market fluctuation; the wholesale price and order quantity increase with the increases in risk aversion and market fluctuation, while the retail price decreases with the increases in risk aversion and market fluctuation.

Proof. The first-order derivatives of $k$ and $\sigma$ are obtained by formulas (23)-(25) as follows:

$$
\begin{aligned}
\frac{\partial p_{m d}}{\partial k} & =0, \\
\frac{\partial p_{m d}}{\partial \sigma} & =0, \\
\frac{\partial w_{m}}{\partial k} & =\frac{\varphi \sigma}{2 \alpha_{r}}>0, \\
\frac{\partial w_{m}}{\partial \sigma} & =\frac{\varphi k}{2 \alpha_{r}}>0, \\
\frac{\partial p_{m r}}{\partial k} & =-\frac{\varphi \sigma}{4 \alpha_{r}}<0, \\
\frac{\partial p_{m r}}{\partial \sigma} & =-\frac{\varphi k}{4 \alpha_{r}}<0, \\
\frac{\partial Q_{m}}{\partial k} & =\frac{\varphi\left(\alpha_{r}-\beta\right) \sigma}{4 \alpha_{r}}>0, \\
\frac{\partial Q_{m}}{\partial \sigma} & =\frac{\varphi\left(\alpha_{r}-\beta\right) k}{4 \alpha_{r}}>0 .
\end{aligned}
$$

We can see that Proposition 2 is proved.
Proposition 2 shows that, in the manufacturer-led Stackelberg game, the direct selling price has nothing to do with the risk aversion of the retailer and market fluctuations, but the wholesale price and order quantity are positively correlated with the risk aversion of the retailer and market fluctuations, and the retail price is negatively correlated with the risk aversion of the retailer and market fluctuations. In the noncooperative game dominated by the manufacturer, the manufacturer will increase wholesale prices to earn more benefits, while the retailer will reduce retail prices to avoid risks and then obtain a greater market share, thus increasing the interest conflicts between the manufacturer and retailer.

3.3. Models under the Dominant Retailer and the Risk-Averse Manufacturer. In the retailer-led models, the manufacturer first decides the wholesale price and direct price, and the retailer decides the retail price; the models can be solved by backward induction.

First, according to Shi et al. [28] and Liu et al. [29], the profit of the retailer is supposed to be $m$; then $m=p_{r}-w$, so $p_{r}=w+m$, from which the utility function of the manufacturer is obtained as follows:

$$
\begin{aligned}
u\left(\pi_{m}\right)= & E\left(\pi_{m}\right)-k \sqrt{\operatorname{var}\left(\pi_{m}\right)} \\
= & w\left[\varphi a-\alpha_{r}(w+m)+\beta p_{d}\right]+p_{d}\left[(1-\varphi) a-\alpha_{d} p_{d}\right. \\
& +\beta(w+m)]-k \sigma\left[\varphi w+(1-\varphi) p_{d}\right] .
\end{aligned}
$$

It is known that the first-order derivatives of $p_{r d}$ and $w_{r}$ are obtained by the utility function of the manufacturer:

$$
\begin{aligned}
& \frac{\partial \pi_{c}}{\partial w}=\varphi(a-k \sigma)-2 \alpha_{r} w+2 \beta p_{d}-\alpha_{r} m, \\
& \frac{\partial \pi_{c}}{\partial p_{d}}=(1-\varphi)(a-k \sigma)-2 \alpha_{d} p_{d}+2 \beta w+\beta m .
\end{aligned}
$$

Then, the Hessel matrix is definitely positive, so there is the optimal wholesale price and direct price. Combining formulas (29) and (30), the optimal wholesale price $w_{r}$ and direct price $p_{r d}$ are obtained as follows:

$$
\begin{aligned}
p_{r d} & =\frac{(a-k \sigma)\left[\varphi \beta+(1-\varphi) \alpha_{r}\right]}{2\left(\alpha_{r} \alpha_{d}-\beta^{2}\right)}, \\
w_{r} & =\frac{(a-k \sigma)\left[\varphi \alpha_{d}+(1-\varphi) \beta\right] a}{\alpha_{r} \alpha_{d}-\beta^{2}}-p_{r} .
\end{aligned}
$$

Inserting $p_{r d}$ and $w_{r}$ into the expected profit function of the retailer yields the new function $E\left(\pi_{r}\right)$ :

$$
\begin{aligned}
E\left(\pi_{r}\right)= & \left(p_{r}-w\right) D_{r} \\
= & \left(2 p_{r}-\frac{(a-k \sigma)\left[(1-\varphi) \beta+\varphi \alpha_{d}\right]}{\alpha_{r} \alpha_{d}-\beta^{2}}\right) \\
& \cdot\left(\varphi a-\alpha_{r} p_{r}+\frac{\beta(a-k \sigma)\left[\varphi \beta+(1-\varphi) \alpha_{r}\right]}{2\left(\alpha_{r} \alpha_{d}-\beta^{2}\right)}\right) .
\end{aligned}
$$


Then, the first-order derivative of $p_{r r}$ is obtained according to $E\left(\pi_{r}\right)$ :

$$
\frac{\partial E\left(\pi_{r}\right)}{\partial p_{r}}=-4 \alpha_{r} p_{r}+2 \varphi a+\frac{(a-k \sigma)\left[\varphi\left(\alpha_{r}^{2}+\beta^{2}\right)+2(1-\varphi) \beta \alpha_{r}\right]}{\alpha_{r} \alpha_{d}-\beta^{2}} .
$$

Letting the first derivative be equal to zero yields the optimal retail price $p_{r r}$ :

$$
p_{r r}=\frac{(a-k \sigma)\left[\varphi\left(\alpha_{r}^{2}+\beta^{2}\right)+2(1-\varphi) \beta \alpha_{r}\right]}{4 \alpha_{r}\left(\alpha_{r} \alpha_{d}-\beta^{2}\right)}+\frac{\varphi a}{2 \alpha_{r}} .
$$

Inserting formula (34) into formulas (26) and (29), the optimal wholesale price $w_{r}$, the optimal direct price $p_{r d}$, and the optimal order quantity $Q_{r}$ are obtained in the retailer-led models

$$
\begin{aligned}
w_{r} & =\frac{(a-k \sigma)\left[(1-\varphi)\left(3 \alpha_{r} \alpha_{d}+\beta^{2}\right)+2 \varphi \beta \alpha_{r}\right]}{4 \alpha_{r}\left(\alpha_{r} \alpha_{d}-\beta^{2}\right)}-\frac{\varphi a}{2 \alpha_{r}}, \\
p_{r d} & =\frac{(a-k \sigma)\left[\varphi \beta+(1-\varphi) \alpha_{r}\right]}{2\left(\alpha_{r} \alpha_{d}-\beta^{2}\right)}, \\
Q_{r} & =E(D)=\frac{(a+k \sigma)\left[\varphi \beta+(2-\varphi) \alpha_{r}\right]}{4 \alpha_{r}} .
\end{aligned}
$$

Proposition 3. When the retailer is dominant, and the manufacturer is risk averse, the retail price, wholesale price, and direct selling price decrease with the increases in risk aversion and market fluctuations, but the order quantity is the opposite.

Proof. The first derivatives of $k$ and $\sigma$ are obtained according to formulas (34)-(37):

$$
\begin{aligned}
& \frac{\partial p_{r r}}{\partial k}=-\frac{\sigma\left[\varphi\left(\alpha_{r}^{2}+\beta^{2}\right)+2(1-\varphi) \beta \alpha_{r}\right]}{4 \alpha_{r}\left(\alpha_{r} \alpha_{d}-\beta^{2}\right)}<0, \\
& \frac{\partial p_{r r}}{\partial \sigma}=-\frac{k\left[\varphi\left(\alpha_{r}^{2}+\beta^{2}\right)+2(1-\varphi) \beta \alpha_{r}\right]}{4 \alpha_{r}\left(\alpha_{r} \alpha_{d}-\beta^{2}\right)}<0, \\
& \frac{\partial w_{r}}{\partial k}=-\frac{\sigma\left[(1-\varphi)\left(3 \alpha_{r} \alpha_{d}+\beta^{2}\right)+2 \varphi \beta \alpha_{r}\right]}{4 \alpha_{r}\left(\alpha_{r} \alpha_{d}-\beta^{2}\right)}<0, \\
& \frac{\partial w_{r}}{\partial \sigma}=-\frac{k\left[(1-\varphi)\left(3 \alpha_{r} \alpha_{d}+\beta^{2}\right)+2 \varphi \beta \alpha_{r}\right]}{4 \alpha_{r}\left(\alpha_{r} \alpha_{d}-\beta^{2}\right)}<0, \\
& \frac{\partial p_{r d}}{\partial k}=-\frac{\sigma\left[(1-\varphi) \alpha_{r}+\varphi \beta\right]}{2\left(\alpha_{r} \alpha_{d}-\beta^{2}\right)}<0, \\
& \frac{\partial p_{r d}}{\partial \sigma}=-\frac{k\left[(1-\varphi) \alpha_{r}+\varphi \beta\right]}{2\left(\alpha_{r} \alpha_{d}-\beta^{2}\right)}<0, \\
& \frac{\partial Q_{r}}{\partial k}=\frac{\sigma\left[(2-\varphi) \alpha_{r}+\varphi \beta\right]}{4 \alpha_{r}}>0, \\
& \frac{\partial Q_{r}}{\partial \sigma}=\frac{k\left[(2-\varphi) \alpha_{r}+\varphi \beta\right]}{4 \alpha_{r}}>0 .
\end{aligned}
$$

Therefore, Proposition 3 can be proved.

It can be seen from Proposition 3 that, in the game structure dominated by the retailer, the risk aversion of the manufacturer and market fluctuations can reduce the retail price, direct selling price, and wholesale price, and the manufacturer will reduce the direct selling price and wholesale price to avoid risks. Although the retailer is dominant, the risk aversion and market fluctuations of the manufacturer also affect the final decision of the retailer; that is, increasing sales can be achieved by reducing the retail price.

3.4. Models under the Nash Equilibrium Structure. In the Nash equilibrium structure, the manufacturer and the retailer are risk averse and make decisions at the same time; 
that is, the manufacturer decides the wholesale price and the direct selling price, and the retailer decides the retail price simultaneously.

Combining formulas (17), (29), and (30), the optimal retail price $p_{n r}$, the optimal direct selling price $p_{n d}$, the optimal wholesale price $w_{n}$, and the optimal order quantity $Q_{n}$ can be obtained as follows:

$$
\begin{aligned}
& p_{n r}=\frac{(a-k \sigma)\left[\varphi\left(4 \alpha_{r} \alpha_{d}-\beta^{2}\right)+3(1-\varphi) \beta \alpha_{r}\right]}{6 \alpha_{r}\left(\alpha_{r} \alpha_{d}-\beta^{2}\right)}, \\
& p_{n d}=\frac{(a-k \sigma)\left[\varphi \beta+(1-\varphi) \alpha_{r}\right]}{2\left(\alpha_{r} \alpha_{d}-\beta^{2}\right)}, \\
& w_{n}=\frac{(a-k \sigma)\left[\varphi\left(2 \alpha_{r} \alpha_{d}+\beta^{2}\right)+3(1-\varphi) \beta \alpha_{r}\right]}{6 \alpha_{r}\left(\alpha_{r} \alpha_{d}-\beta^{2}\right)}, \\
& Q_{n}=E(D)=\frac{a+k \sigma}{2}-\frac{\varphi(a-k \sigma)\left(\alpha_{r}-\beta\right)}{6 \alpha_{r}} .
\end{aligned}
$$

Proposition 4. Under the Nash equilibrium structure, the degree of risk aversion and market fluctuations are negatively correlated with the retail price, direct selling price, and wholesale price and are positively correlated with the order quantity.

Proof. The first-order partial derivatives of $k$ and $\sigma$ can be obtained by formulas (39)-(42):

$$
\begin{aligned}
& \frac{\partial P_{n r}}{\partial k}=-\frac{\sigma\left[\varphi\left(4 \alpha_{r} \alpha_{d}-\beta^{2}\right)+3(1-\varphi) \beta \alpha_{r}\right]}{6 \alpha_{r}\left(\alpha_{r} \alpha_{d}-\beta^{2}\right)}<0, \\
& \frac{\partial P_{n r}}{\partial \sigma}=-\frac{k\left[\varphi\left(4 \alpha_{r} \alpha_{d}-\beta^{2}\right)+3(1-\varphi) \beta \alpha_{r}\right]}{6 \alpha_{r}\left(\alpha_{r} \alpha_{d}-\beta^{2}\right)}<0, \\
& \frac{\partial p_{n d}}{\partial k}=-\frac{\sigma\left[\beta \varphi(1-\varphi) \alpha_{r}\right]}{2\left(\alpha_{r} \alpha_{d}-\beta^{2}\right)}<0, \\
& \frac{\partial p_{n d}}{\partial \sigma}=-\frac{k\left[\beta \varphi(1-\varphi) \alpha_{r}\right]}{2\left(\alpha_{r} \alpha_{d}-\beta^{2}\right)}<0, \\
& \frac{\partial w_{n}}{\partial k}=-\frac{\sigma\left[\varphi\left(2 \alpha_{r} \alpha_{d}+\beta^{2}\right)+3(1-\varphi) \beta \alpha_{r}\right]}{6 \alpha_{r}\left(\alpha_{r} \alpha_{d}-\beta^{2}\right)}<0, \\
& \frac{\partial w_{n}}{\partial \sigma}=-\frac{k\left[\varphi\left(2 \alpha_{r} \alpha_{d}+\beta^{2}\right)+3(1-\varphi) \beta \alpha_{r}\right]}{6 \alpha_{r}\left(\alpha_{r} \alpha_{d}-\beta^{2}\right)}<0, \\
& \frac{\partial Q_{n}}{\partial k}=\frac{\left[\sigma\left(4 \alpha_{r}-\beta\right)\right]}{6 \alpha_{r}}>0, \\
& \frac{\partial Q_{n}}{\partial \sigma}=\frac{k\left[\left(4 \alpha_{r}-\beta\right)\right]}{6 \alpha_{r}}>0 .
\end{aligned}
$$

It can be seen that Proposition 4 is proved.
It can be seen from Proposition 4 that, under the Nash equilibrium structure, the manufacturer reduces the direct selling price and wholesale price to avoid risk, the retailer reduces retail prices and increases the order quantity to avoid risk at the same time, and the conclusion is similar to Proposition 3, while the extent of price reductions and order quantity increases is different. In addition, risk aversion and market fluctuations also reduce the performance of supply chains.

From Proposition 1 to Proposition 4, it can be seen that, regardless of power structure, risk aversion and market fluctuations are negatively correlated with retail prices and positively correlated with order quantity, indicating that the retailer is greatly affected. Under a manufacturer-led structure, risk aversion and market fluctuations are independent of direct selling prices, positively correlated with wholesale prices, and negatively correlated with retail prices, direct selling prices, and wholesale prices in other game structures, indicating that the game model under a dominant manufacturer and risk-averse retailer has a greater impact on the decisions of dual-channel supply chains. In addition, the results of Nash equilibrium decisions are close to those in a centralized supply chain, indicating that the double marginal effect of supply chains can be reduced to some extent in the Nash equilibrium structure.

\section{Comparative Analysis of Dual-Channel Supply Chain Decisions under Different Power Structures}

Proposition 5. Under different power structures, the direct selling price has the following relationship:

$$
p_{m d}>p_{c d}=p_{r d}=p_{n d} .
$$

Proof. From formulas (23) and (11), it can be determined that the relationship between $p_{m d}$ and $p_{c d}$ is as follows:

$$
\begin{aligned}
p_{m d}-p_{c d} & =\frac{\left[\varphi \beta+(1-\varphi) \alpha_{r}\right] a}{2\left(\alpha_{r} \alpha_{d}-\beta^{2}\right)}-\frac{(a-k \sigma)\left[\varphi \alpha_{d}+(1-\varphi) \beta\right]}{2\left(\alpha_{r} \alpha_{d}-\beta^{2}\right)} \\
& =\frac{\left[\varphi \alpha_{d}+(1-\varphi) \beta\right] k \sigma}{2\left(\alpha_{r} \alpha_{d}-\beta^{2}\right)}>0 .
\end{aligned}
$$

Furthermore, from formulas (11), (36), and (40), it can be obtained that $p_{c d}=p_{r d}=p_{n d}$.

Thus, Proposition 5 is proved.

From Proposition 5, it can be seen that, under the game structure dominated by the manufacturer, the direct selling price is the largest, and the direct selling price is the same in the centralized structure and the retailer-led and the Nash equilibrium structures because the direct selling price is not affected by risk aversion when the manufacturer is a leader. It is also an indirect statement that the risk aversion will reduce the direct selling price under other power structures. It further shows that the impact of the manufacturer-led 
power structure on the direct selling price is greater than that the influences of risk aversion and market fluctuations on the direct selling price since there exist risk aversion and market fluctuations in other power structures, but the direct selling price is the same; otherwise, the direct selling price should be the same under any power structure.
Proposition 6. Under different power structures, the retail price satisfies the following relationships:

$$
p_{m r}>p_{r r}>p_{n r}>p_{c r}
$$

Proof. From formulas (10), (25), (34), and (39), the results are as follows:

$$
\begin{aligned}
p_{m r}-p_{r r} & =\frac{\left[\varphi\left(\beta^{2}+\alpha_{r} \alpha_{d}\right)+2(1-\varphi) \beta \alpha_{r}\right] a}{4 \alpha_{r}\left(\alpha_{r} \alpha_{d}-\beta^{2}\right)}+\frac{\varphi(2 a-k \sigma)}{4 \alpha_{r}}-\frac{(a-k \sigma)\left[\varphi\left(\alpha_{r}^{2}+\beta^{2}\right)+2(1-\varphi) \beta \alpha_{r}\right]}{4 \alpha_{r}\left(\alpha_{r} \alpha_{d}-\beta^{2}\right)}+\frac{\varphi a}{2 \alpha_{r}} \\
& =\frac{\beta\left[\varphi \beta+(1-\varphi) \alpha_{r}\right]}{2 \alpha_{r}\left(\alpha_{r} \alpha_{d}-\beta^{2}\right)}>0, \\
p_{r r}-p_{n r} & =\frac{(a-k \sigma)\left[\varphi\left(\alpha_{r}^{2}+\beta^{2}\right)+2(1-\varphi) \beta \alpha_{r}\right]}{4 \alpha_{r}\left(\alpha_{r} \alpha_{d}-\beta^{2}\right)}+\frac{\varphi a}{2 \alpha_{r}}-\frac{(a-k \sigma)\left[\varphi\left(4 \alpha_{r} \alpha_{d}+\beta^{2}\right)+3(1-\varphi) \beta \alpha_{r}\right]}{6 \alpha_{r}\left(\alpha_{r} \alpha_{d}-\beta^{2}\right)} \\
& =\frac{\varphi(a+5 k \sigma)}{12 \alpha_{r}}>0, \\
p_{n r}-p_{c r} & =\frac{(a-k \sigma)\left[\varphi\left(4 \alpha_{r} \alpha_{d}-\beta^{2}\right)+3(1-\varphi) \beta \alpha_{r}\right]}{6 \alpha_{r}\left(\alpha_{r} \alpha_{d}-\beta^{2}\right)}-\frac{(a-k \sigma)\left[\varphi \alpha_{d}+(1-\varphi) \beta\right]}{2\left(\alpha_{r} \alpha_{d}-\beta^{2}\right)} \\
& =\frac{\varphi(a-k \sigma)}{6 \alpha_{r}}>0 .
\end{aligned}
$$

Proposition 6 is proved from the procedure above.

First, from Proposition 6, we can see that the retail price of the decentralized supply chain is greater than that of the centralized supply chain, which shows that the retailer will achieve its goal by increasing retail prices under certain conditions to obtain more benefits in a noncooperative game, similar to the traditional supply chain. Second, the retail price under the structure led by the manufacturer is the largest, and the retail price is the smallest under the centralized structure, showing that the retail price is not only affected by risk aversion and market fluctuations but also by the wholesale price because, under the manufacturer's leadership, the manufacturer increases the wholesale price to maximize its own income, leading to an increase in retail price, which will directly reduce the market demand and reduce the supply chain performance.

Proposition 7. In the decentralized supply chain, there is a relationship between the wholesale prices under different power structures: $w_{m}>w_{n}>w_{r}$.

Proof. From formulas (24), (35), and (41), the results can be obtained as follows:

$$
\begin{aligned}
w_{m}-w_{n} & =\frac{\left[\varphi \alpha_{d}+(1-\varphi) \beta\right] a}{2\left(\alpha_{r} \alpha_{d}-\beta^{2}\right)}+\frac{\varphi k \sigma}{2 \alpha_{r}}-\frac{(a-k \sigma)\left[\varphi\left(2 \alpha_{r} \alpha_{d}+\beta^{2}\right)+3(1-\varphi) \beta \alpha_{r}\right]}{6 \alpha_{r}\left(\alpha_{r} \alpha_{d}-\beta^{2}\right)} \\
& =\frac{\varphi(a+3 k \sigma)}{6 \alpha_{r}}+\frac{\left[\varphi\left(2 \alpha_{r} \alpha_{d}+\beta^{2}\right)+3(1-\varphi) \beta \alpha_{r}\right] k \sigma}{6 \alpha_{r}\left(\alpha_{r} \alpha_{d}-\beta^{2}\right)}>0, \\
w_{n}-w_{r} & =\frac{(a-k \sigma)\left[\varphi\left(2 \alpha_{r} \alpha_{d}+\beta^{2}\right)+3(1-\varphi) \beta \alpha_{r}\right]}{6 \alpha_{r}\left(\alpha_{r} \alpha_{d}-\beta^{2}\right)}-\frac{(a-k \sigma)\left[(1-\varphi)\left(3 \alpha_{r} \alpha_{d}+\beta^{2}\right)+2 \varphi \beta \alpha_{r}\right]}{4 \alpha_{r}\left(\alpha_{r} \alpha_{d}-\beta^{2}\right)}+\frac{\varphi a}{2 \alpha_{r}} \\
& =\frac{\left[(13 \varphi-9) \alpha_{r} \alpha_{d}+(5 \varphi-3) \beta^{2}+(6-12 \varphi) \beta \alpha_{r}\right] a-\left[(13 \varphi-9) \alpha_{r} \alpha_{d}+(5 \varphi-3) \beta^{2}+(6-12 \varphi) \beta \alpha_{r}\right] k \sigma}{12 \alpha_{r}\left(\alpha_{r} \alpha_{d}-\beta^{2}\right)}+\frac{\varphi a}{2 \alpha_{r}} \\
& >0+\frac{\varphi a}{2 \alpha_{r}}>0 .
\end{aligned}
$$


Proposition 7 is proved.

Proposition 7 shows that the wholesale price is the largest under the structure of a risk-averse retailer and a dominant manufacturer, the wholesale price is the smallest under the structure of a risk-averse manufacturer and a dominant retailer, and the wholesale price is decided by the manufacturer, demonstrating that the power structure has a great influence on the wholesale price. At the same time, according to Propositions 2-4, it can be seen that the wholesale price is positively correlated with risk aversion and market fluctuations when the manufacturer is dominant, while the wholesale price is negatively correlated with risk aversion and market fluctuations under the retailer-led structure and Nash equilibrium structure, so the wholesale price is the greater in the manufacturer-led structure.

Proposition 8. Under the different power structures, the order quantity satisfies the following relationship: $Q_{c}>Q_{n}>Q_{r}>Q_{m}$.

Proof. From formulas (12), (26), (37), and (42), it can be seen that the comparison expressions are valid as follows:

$$
\begin{aligned}
Q_{c}-Q_{n}= & \frac{(a+k \sigma)}{2}-\frac{a}{2}+\frac{\varphi(a-k \sigma)}{6 \alpha_{r}} \\
= & \frac{\varphi(a-k \sigma)}{6 \alpha_{r}}>0 \\
Q_{n}-Q_{r}= & \frac{(a+k \sigma)}{2}-\frac{\varphi\left(\alpha_{r}-\beta\right)(a-k \sigma)}{6 \alpha_{r}} \\
& -\frac{(a+k \sigma)\left[\varphi \beta+(2-\varphi) \alpha_{r}\right]}{4 \alpha_{r}} \\
= & \frac{\varphi\left(\alpha_{r}-\beta\right)(a+5 k \sigma)}{12 \alpha_{r}}>0, \\
Q_{r}-Q_{m}= & \frac{(a+k \sigma)\left[\varphi \beta+(2-\varphi) \alpha_{r}\right]}{4 \alpha_{r}}-\frac{a}{2}+\frac{\varphi(a-k \sigma)\left(\alpha_{r}-\beta\right)}{4 \alpha_{r}} \\
= & \frac{k \sigma(1-\varphi)\left(\alpha_{r}+\varphi \beta\right)}{2 \alpha_{r}}>0 .
\end{aligned}
$$

Therefore, Proposition 8 is proved.

As seen from Proposition 8, the order quantity in the centralized structure is the largest, which is the same as that of the traditional supply chain, and the order quantity under the centralized supply chain is the largest under the cooperative game whether or not there is risk aversion and market fluctuation. In the decentralized supply chain, the order quantity is the smallest under the manufacturer-led structure because the direct selling price is the highest in the four power structures, and the wholesale price is also the largest, increasing the retail price that is the largest for the retailer, which wants to maximize the profit and reduce the market demand to a certain extent. Under the Nash equilibrium structure, both the manufacturer's and the retailer's risk aversion and simultaneous decision-making will greatly reduce the bilateral effect caused by the asymmetric information.

\section{Example Analysis}

To verify the above propositional conclusions and find potentially valuable information for this example, the relevant parameters are set according to the research assumptions and conditions as follows: $a=100, \alpha_{r}=\alpha_{d}=2$, $\beta=1, \sigma=2, \varphi=0.6$, and $k=1$.

It can be seen that the given data meet the assumptions according to the following comparison expression: $\alpha_{r} \alpha_{d}-\beta^{2}>0$.

\subsection{Decision Comparison of the Dual-Channel Supply Chain.} It can be seen from Table 1 that the total profit of the centralized supply chain is the greatest, showing that the parameters of the centralized supply chain are optimal, and the overall optimization can be realized; the total profit of the supply chain is the smallest when the manufacturer dominates the supply chain. At the same time, we can also see that the profit and utility of the manufacturer and the retailer are the greatest under their own domination, indicating that, in the decentralized supply chain, each wants to maximize its own profit, leading to increased selling prices, which affect market demand. In addition, due to the influence of risk aversion and market fluctuation, the utilities of the manufacturer and retailer are obviously less than their respective profits, indicating that risk aversion and market fluctuation reduce the efficiency of the supply chain.

5.2. Impacts of Risk Aversion and Market Fluctuations on Supply Chain Profits under Different Power Structures. To show more clearly and intuitively the influence of risk aversion and market fluctuations on supply chain decisionmaking, this part considers risk aversion and market fluctuations as the unknown parameters, and the remaining parameters are established according to the data in this chapter. Simulation analysis will be performed using MATLAB software, version 2014.

\subsubsection{Influences of Risk Aversion and Market Fluctuations on} the Profits of the Supply Chain under the Centralized Structure. It can be seen from Figure 2 that the total profits of the centralized supply chain decrease with the increases in risk aversion and market fluctuations at the same time, and the changing trends of risk aversion and market fluctuation regarding the supply chain are the same; that is, all of them are the open-down parabolas under given conditions. At the same time, it can be seen from Figure 2 that the profits of the centralized supply chain reach the maximum without risk aversion or market fluctuations.

5.2.2. Influences of Risk Aversion and Market Fluctuations on Supply Chain Profits under the Manufacturer-Dominant Structure. It can be seen from Figure 3 that the profit of the 
TABLE 1: The value of the dual-channel supply chain.

\begin{tabular}{lcccc}
\hline $\begin{array}{l}\text { Decision } \\
\text { parameters }\end{array}$ & $\begin{array}{c}\text { Power structure } \\
\text { Centralized structure } \\
\text { (c) }\end{array}$ & $\begin{array}{c}\text { Manufacturer-dominant } \\
(\mathrm{m}-\mathrm{s})\end{array}$ & $\begin{array}{c}\text { Retructure } \\
\text { Retailer-dominant structure } \\
(\mathrm{r}-\mathrm{s})\end{array}$ & $\begin{array}{c}\text { Nash equilibrium structure } \\
(\mathrm{n})\end{array}$ \\
\hline$p_{d}$ & 23.19 & 23.33 & 23.19 & 23.19 \\
$p_{r}$ & 26.13 & 34.02 & 33.78 & 31.03 \\
$w$ & & 26.97 & 16.03 & 21.23 \\
$Q$ & 51 & 42.65 & 43.35 & 46.1 \\
$E(\pi)$ & 1266.20 & 1162.67 & 1163.39 & 1227.29 \\
$E\left(\pi_{m}\right)$ & & 1054.88 & 885.96 & 1020.22 \\
$E\left(\pi_{T}\right)$ & & 107.79 & 277.43 & 207.07 \\
$u_{m}$ & & 1054.83 & 848.17 & 932.14 \\
$u_{r}$ & & 99.33 & 277.43 & 195.31 \\
\hline
\end{tabular}

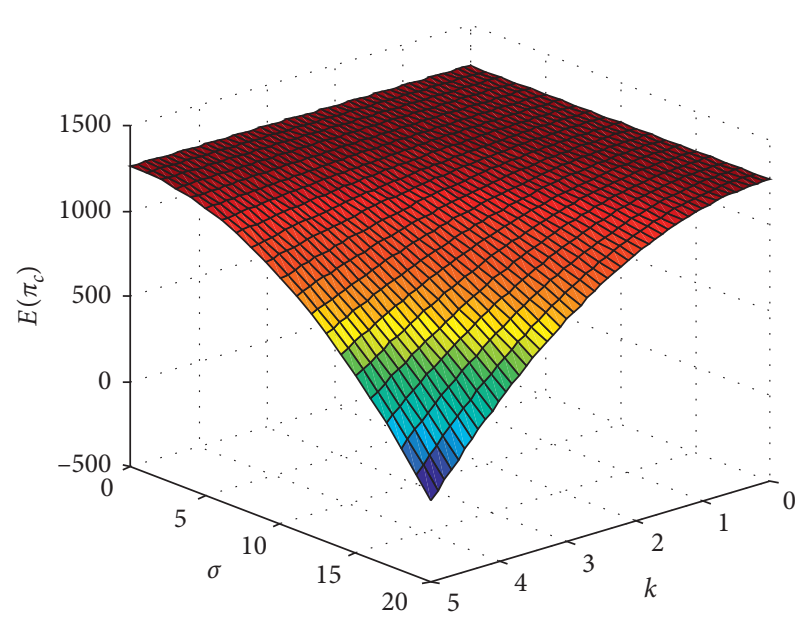

FIgURE 2: The trend of total profit in the supply chain under the centralized structure.

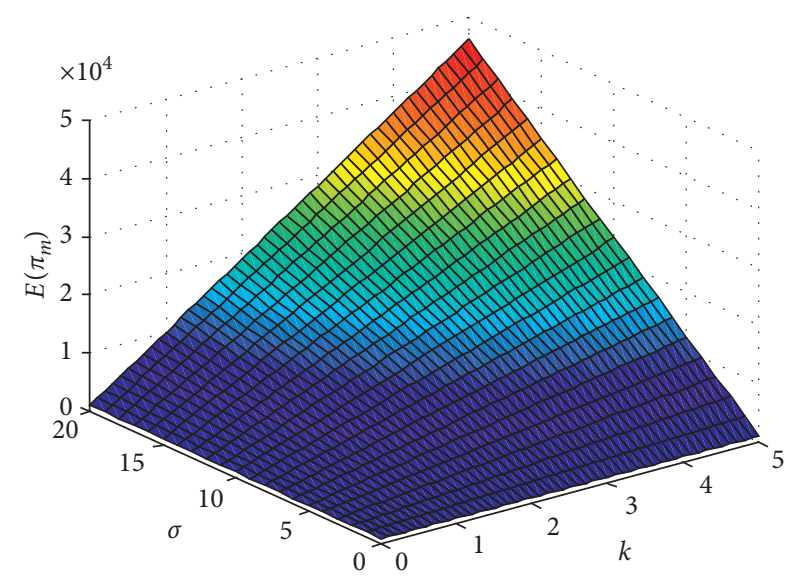

Figure 3: The trend of the manufacturer's profits under the manufacturer-dominant structure.

manufacturer increases with the increases in risk aversion and market fluctuation. When the risk aversion of the retailer and the fluctuations of market demand reach the maximum, the profits of the manufacture are maximized, showing that the risk aversion of the retailer is positively correlated with market fluctuations because, when the manufacturer is dominant and the retailer is risk averse, the wholesale price and order quantity increase with the increases in risk aversion and market fluctuation, while the direct selling price remains unchanged, so the manufacturers' profits increase.

Figure 4 shows that the profit of the retailer decreases with the increases in the risk aversion of the retailer and market fluctuation, and the trend is the same under risk aversion and market fluctuations-a parabola with opening facing down. At this time, the power of the retailer is small, and then the risk aversion of the retailer is relatively obvious, and the retail price will be lower. At the same time, market fluctuation will also lead to a decrease in retail price, so the retailer must reduce the retail price in exchange for market share to avoid market risk. In addition, the increase in wholesale price eventually leads to a decrease in total profit, which produces a bilateral effect and aggravates the conflict between the manufacturer and the retailer.

As seen from Figures 3 and 4, risk aversion and market fluctuation will increase the manufacturer's revenue and cause the retailer to lose, producing a profit conflict in the supply chain and bringing greater difficulties to supply chain management.

\subsubsection{Influences of Risk Aversion and Market Fluctuations on} Supply Chain Profits under a Retailer-Dominant Structure. It can be seen from Figure 5 that, when the retailer is dominant and the manufacturer is risk-averse, the manufacturer's profit decreases with the increases in risk aversion and market fluctuation, and the overall trend is the same because risk aversion and market fluctuations reduce the manufacturer's direct sale price and wholesale price. Although the order quantity of the retailer increases, the overall profit of the manufacturer decreases due to the influence of bilateral effects. It can be seen that the trend in the manufacturer's profits is the opposite of Figure 3, which shows that the influences of the power structure, risk aversion, and market fluctuation on the manufacturer's profits are different.

Figure 6 shows that, when the retailer is dominant and the manufacturer is risk averse, the retailers' profits increase with the increases in risk aversion and market fluctuation, and the impacts of risk aversion and market fluctuation on the retailer's profits are the same. Compared with Figure 4, it 


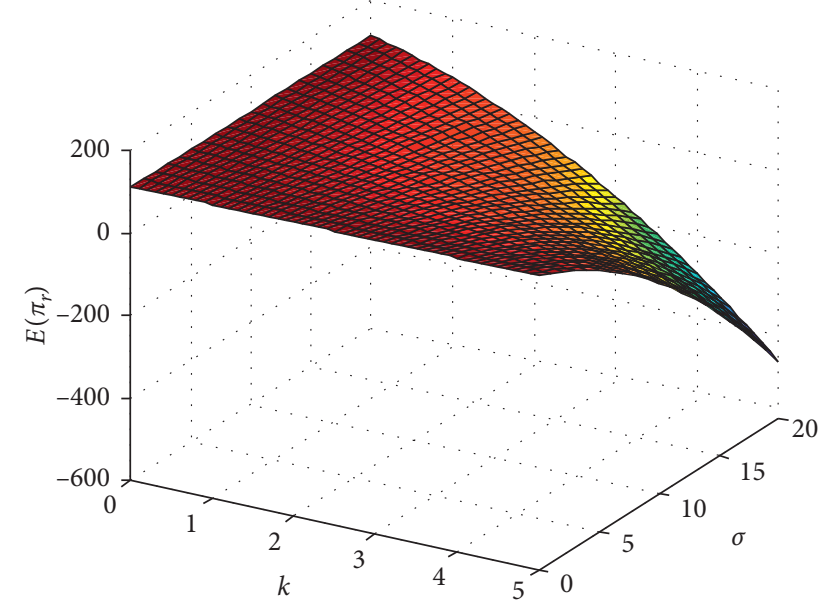

FIgURE 4: The trend of the retailer's profits under the manufacturer-dominant structure.

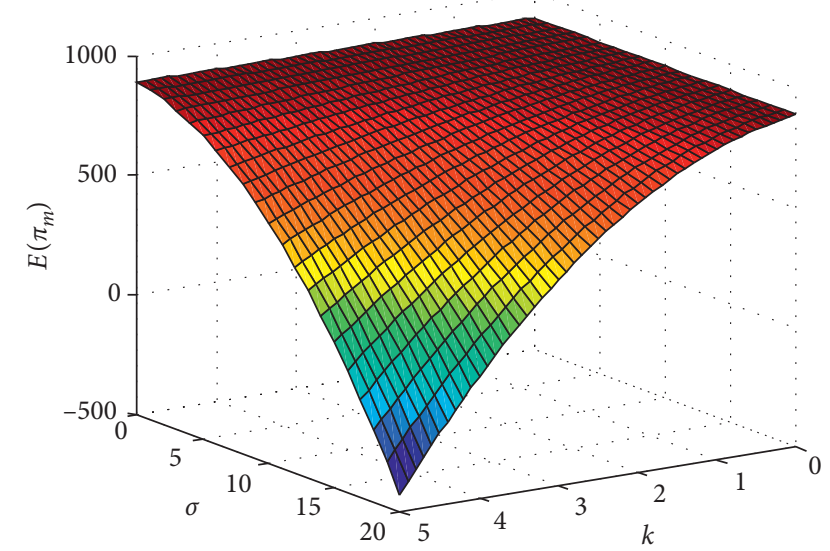

Figure 5: The trend of the manufacturer's profits under the retailer-dominant structure.

can be seen that risk aversion and market fluctuations have the opposite effects on the profits of the retailer under different power structures.

From Figures 3-6, it can be seen that the profits of the dominators under the different power structures are positively correlated with risk aversion and market fluctuation, while the profits of the followers are affected in the opposite manner, showing that the power structure, risk aversion, and market fluctuation affect the interests of the participants in the supply chain.

\subsubsection{Influences of Risk Aversion and Market Fluctuations on} Supply Chains Profit under the Nash Equilibrium Structure. As seen in Figure 7, under the Nash equilibrium structure, the trend in the manufacturer's profit is similar under risk aversion and market fluctuations, except that the magnitude of the change is different. As seen in Figures 3 and 5, the different power structures have different impacts on the manufacturer's decision-making in the case that the risk aversion and market fluctuation are the same.

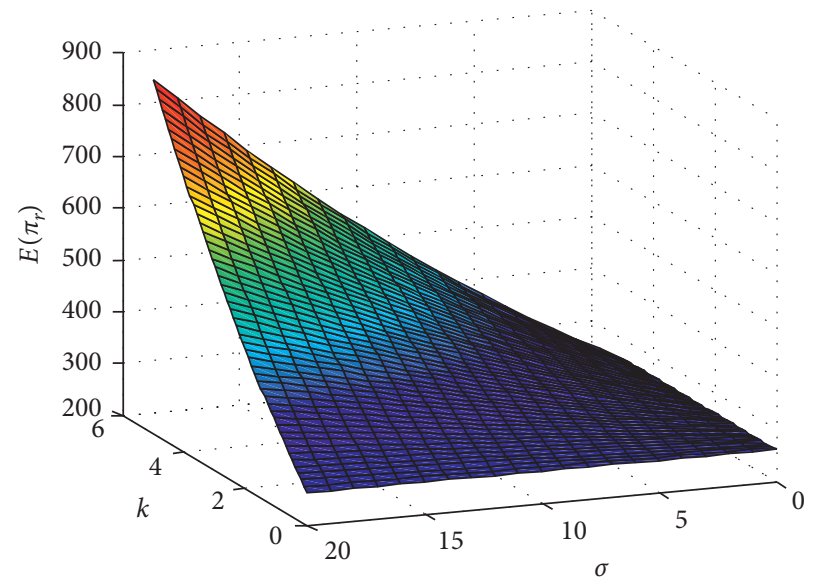

Figure 6: The trend of the retailer's profits under the retailerdominant structure.

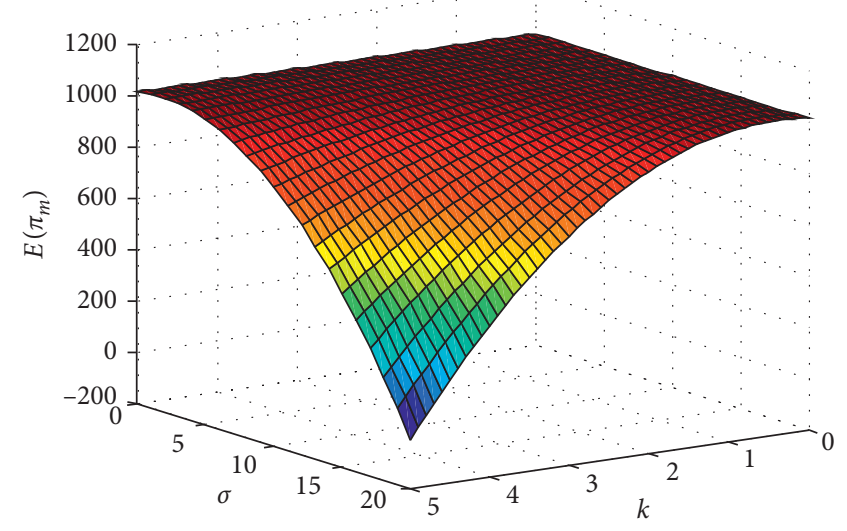

FIgURE 7: The trend of the manufacturer' profits under Nash equilibrium.

Under the Nash equilibrium structure, risk aversion, and small market fluctuations are positively correlated with the retailer's profits when their value is small, whereas they are negatively correlated with the retailer's profit, and the trend in the retailer's profits is an inverted " $u$ " parabola that is maximal and opened downward, changing regularly under the influence of risk aversion and market fluctuation. Compared with Figures 3-8, it can be seen that the different power structures and attitudes toward risk have different effects on the profits of the manufacturer and the retailer in decentralized decision-making. Therefore, we can see that the power structure, risk aversion, and market fluctuation affect the decisions of the supply chain.

From Figures 2-8, the following management implications can be obtained. First, although risk aversion and market fluctuations will affect the decisions of the supply chain, the degree of risk aversion and the size of market fluctuations are not unlimited, so the upper limit of the retail price, wholesale price, and direct selling price cannot be increased all the time, requiring the supply chain to coordinate the conflicts among the stakeholders in the supply chain under the influence of bilateral effects. Second, the 


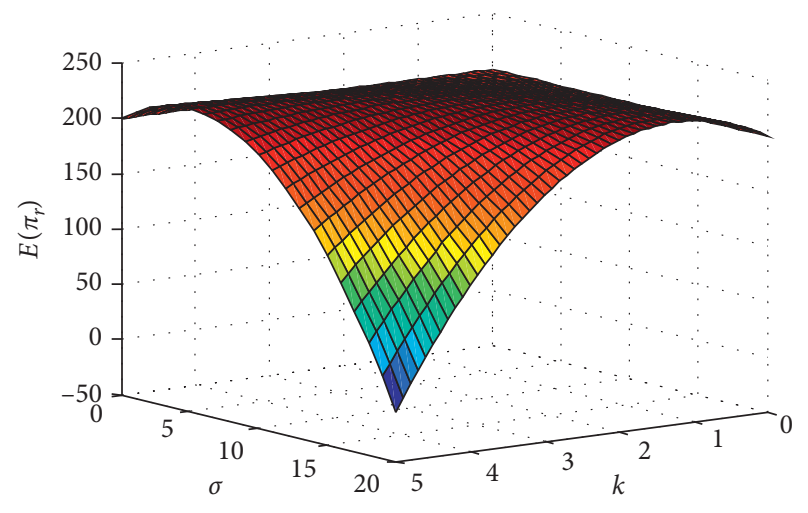

FIgURE 8: The trend of the retailer's profits under the Nash equilibrium structure.

decisions of the dominators are relatively optimal, but under the decentralized decision, the total profits of the supply chain are not maximized. For the supply chain managers, whether there is risk aversion or market fluctuation or not, the conflicts still exist in the decentralized structure. Finally, the profits and utility of supply chains are quadratic functions of risk aversion and market fluctuations, showing that the influences of risk aversion and market fluctuations on the supply chain have a certain regularity. How to reduce the negative effects under the influences of risk aversion and market fluctuation is a practical problem that the managers should consider; after all, uncertain factors always exist in real life, so the risk cannot be avoided.

\section{Conclusions}

This paper studies the dual-channel and risk-averse supply chain with the manufacturer and retailer under stochastic demand and the influences of risk aversion and market fluctuations on the decisions of the manufacturer and retailer in different power structures, and it compares the different decisions and analyzes the influences of power structures, risk aversion, and market fluctuations on the profits of the dual-channel supply chain using example analysis.

Through the above analysis, we draw the following conclusions: first, the direct selling price is not affected by risk aversion or market fluctuations under the manufacturer-dominant structure, and the retail price, the direct selling price, and the wholesale price under the other power structures, except for the manufacturer-dominated structure, are negatively correlated with the risk aversion and market fluctuations, with a strictly monotonically decreasing trend. Second, the order quantity is associated with the risk aversion and market fluctuations, regardless of the power structures, and the order quantity in the centralized structure is maximal and is minimal under the manufacturer-led structure. Finally, the influences of risk aversion and market fluctuations on the participants in the supply chain are different under different power structures, and in the centralized and Nash equilibrium structures, the change curve of supply chain profits is a parabola with a downward opening. The trends of the manufacturer's profits and the retailer's profits are the opposite under the manufacturer-led structure and retailer-led structure.

This paper not only considers the influences of power structures, risk aversion, and market fluctuations on the dual-channel supply chain but also analyzes the behavior of the risk attitudes of the followers using the dominant power structure. The results are thus practical and meaningful. However, the interest conflicts of dual-channel supply chain participants in decentralized decision-making are not analyzed, and future research should examine how to coordinate the profit conflict between the manufacturer and the retailer under different power structures, risk aversion, and market fluctuations so that more complete and practical conclusions can be drawn for supply chain management to provide some experience.

\section{Data Availability}

The data used to support the findings of this study are available from the corresponding author upon request.

\section{Conflicts of Interest}

The authors declare that they have no conflicts of interest.

\section{Acknowledgments}

This research was supported by the National Natural Science Foundation of China (Grant no. 71771055), Key Projects of Natural Science of Anhui (Grant nos. KJ2019A0519 and KJ2018A0354), Ministry of Education Foundation for $\mathrm{Hu}-$ manities and Social Sciences Planning (Grant nos. 17YJAZH018 and AHSKZ2019D003), and Research Project on Innovation and Development of Social Science (Grant no. 2019CX065).

\section{References}

[1] S. J. Li and Z. G. Zhang, "Pricing strategy in risk-averse dualchannel supply chain," Advances in Information Sciences and Service Sciences, vol. 4, no. 5, pp. 78-87, 2012.

[2] G. Xu, B. Dan, X. Zhang, and C. Liu, "Coordinating a dualchannel supply chain with risk-averse under a two-way revenue sharing contract," International Journal of Production Economics, vol. 147, pp. 171-179, 2014.

[3] L. Zhang and Z. Yao, "Decision making for a risk-averse dualchannel supply chain with customer returns," Decision Support Systems III-Impact of Decision Support Systems for Global Environments, vol. 184, pp. 118-130, 2014.

[4] L. L. Zhang and Z. Yao, "Optimal strategy of risk -averse dualchannel supply chain with consumer returns," Computer Integrated Manufacturing Systems, vol. 21, no. 3, pp. 766-775, 2015.

[5] G. Y. Xu and X. M. Zhang, "Coordinating the dual-channel risk-averse supply chain based on price discount," Journal of System and Management, vol. 25, no. 6, pp. 1114-1120, 2016.

[6] B. Yan, Z. J. Jin, Y. P. Liu et al., "Decision on risk-averse dualchannel supply chain under demand disruption," Systems Engineering, vol. 34, no. 8, pp. 116-122, 2016.

[7] B. Yan, Z. Jin, Y. Liu, and J. Yang, "Decision on risk-averse dual-channel supply chain under demand disruption," 
Communications in Nonlinear Science and Numerical Simulation, vol. 55, pp. 206-224, 2018.

[8] S. J. Li, Z. G. Zhang, and Y. Huang, "Effects of risk aversion on operational mode in dual-channel supply chain," Industrial Engineering and Management, vol. 16, no. 1, pp. 32-36, 2011.

[9] B. Li, P.-W. Hou, P. Chen, and Q.-H. Li, "Pricing strategy and coordination in a dual channel supply chain with a risk-averse retailer," International Journal of Production Economics, vol. 178, pp. 154-168, 2016.

[10] M. Liu, E. Cao, and C. K. Salifou, "Pricing strategies of a dualchannel supply chain with risk aversion," Transportation Research Part E: Logistics and Transportation Review, vol. 90, pp. 108-120, 2016.

[11] D. P. Wang, C. X. Gu, and B. Q. Zhang, "Pricing decision in dual-channel supply chain under risk-aversion and asymmetric information," Industrial Engineering and Management, vol. 21, no. 4, pp. 20-34, 2016.

[12] C. Wang, D. L. Yang, and X. Q. Cheng, "A Study of information sharing in dual-channel supply chain with riskpreference retailer," Industrial Engineering and Management, vol. 22, no. 2, pp. 83-96, 2017.

[13] L. Chen and J. S. Hu, "Influence of risk aversion on different types of dual-channel supply chain decision," Journal of Shandong University, vol. 53, no. 5, pp. 30-40, 2018.

[14] C. R. Shen and X. Y. Liu, "Decision of dual-channel supply chain when considering risk aversion and carbon emission reduction," Computer Engineering and Applications, vol. 55, no. 1, pp. 241-247, 2019.

[15] B. Yan and Y. P. Liu, "Decision on risk-averse retailerdominated dual-channel supply chain under demand disruption," Nankai Economic Studies, vol. 2, pp. 73-91, 2016.

[16] Q. Fang, L. Ren, Z. G. Zhang et al., "Research on Pricing Strategy of risk-averse retailer-dominated dual-channel supply chain," Forecasting, vol. 37, no. 1, pp. 68-74, 2018.

[17] H. Wang and J. Zhou, "effect of competition and risk aversion on dual-channel supply chain," Journal of Management Science, vol. 23, no. 1, pp. 10-17, 2010.

[18] B. Li, P. Chen, Q. Li, and W. Wang, "Dual-channel supply chain pricing decisions with a risk-averse retailer," International Journal of Production Research, vol. 52, no. 23, pp. 7132-7147, 2014.

[19] R. M. S. Costa and P. Pavone, "Diachronic biodiversity analysis of a metropolitan area in the Mediterranean region," Acta Horticulturae, vol. 1215, no. 1215, pp. 49-52, 2018.

[20] S. A. Raza and S. M. Govindaluri, "Pricing strategies in a dualchannel green supply chain with cannibalization and risk aversion," Operations Research Perspectives, vol. 6, pp. 100$118,2019$.

[21] H.-S. Lau and A. H.-L. Lau, "Manufacturer's pricing strategy and return policy for a single-period commodity," European Journal of Operational Research, vol. 116, no. 2, pp. 291-304, 1999.

[22] T.-M. Choi, D. Li, and H. Yan, "Mean-variance analysis of a single supplier and retailer supply chain under a returns policy," European Journal of Operational Research, vol. 184, no. 1, pp. 356-376, 2008.

[23] H. Wang and J. Zhou, "Optimal strategies of dual channel with risk a verse members," Computer Integrated Manufacturing Systems, vol. 15, no. 11, pp. 2242-2246, 2009.

[24] G. Hua, S. Wang, and T. C. E. Cheng, "Price and lead time decisions in dual-channel supply chains," European Journal of Operational Research, vol. 205, no. 1, pp. 113-126, 2010.

[25] S. Huang, C. Yang, and H. Liu, "Pricing and production decisions in a dual-channel supply chain when production costs are disrupted," Economic Modelling, vol. 30, pp. 521-538, 2013.

[26] F. Ding and J. Z. Huo, "Study on the effect of service for coordination strategy of dual-channel supply chain," Chinese Jurnal of Management Science, vol. 22, pp. 485-490, 2014.

[27] J. Zhang, L. Lei, S. Zhang, and L. Song, "Dynamic vs. static pricing in a supply chain with advertising," Computers and Industrial Engineering, vol. 109, pp. 266-279, 2017.

[28] R. Shi, J. Zhang, and J. Ru, "Impacts of power structure on supply chains with uncertain demand," Production and Operations Management, vol. 22, no. 5, pp. 1232-1249, 2013.

[29] G. Liu, T. Yang, Y. Wei, and X. Zhang, "Decisions of green supply chain under fairness concerns and different power structures," International Journal of Enterprise Information Systems, vol. 14, no. 4, pp. 28-53, 2018. 